\title{
In Situ Resource-Based Lunar and Martian Habitat Structures Development at NASA/MSFC
}

\author{
Melanie P. Bodiford* \\ NASAMarshall Space Flight Center, Huntsville, AL, 35812 \\ Michael R. Fiske ${ }^{\dagger}$ and Walter McGregor \\ Morgan Research Corporation, Huntsville, AL, 35805 \\ and \\ Regina D. Pope $e^{\ddagger}$ \\ Qualis Corporation, Huntsville, AL, 35805
}

\begin{abstract}
As the nation prepares to return to the Moon and subsequently to Mars, it is apparent that the viability of long duration visits with appropriate radiation shielding/crew protection, hinges on the development of habitat structures, preferably in advance of a manned landing, and preferably utilizing in-situ resources. A relatively large number of habitat structure configurations can be developed from a relatively small set of in-situ resource-based construction products, including, blocks, raw regolith, reinforced concrete, and glass products. A much larger group of habitat designs can be developed when "imported" material are brought from Earth, including thin films and liners, and foldable, or expandable metal structures. These, and other technologies have been identified, and subjected to a rigorous trade study evaluation with respect to exploration and other performance criteria.

In this paper, results of this trade study will be presented, as well as various habitat structure design concepts and concepts for construction automation. Results of initial tests aimed at concrete, block and glass production using Lunar regolith simulants will also be presented. Key issues and concerns will be discussed, as well as design concepts for a Lunar environment testbed to be developed at MSFC's Microgravity Development Laboratory. (MDL).
\end{abstract}

\section{Introduction}

As the nation prepares to return to the Moon and subsequently to Mars, it is apparent that the viability of long duration visits with appropriate radiation shielding/crew protection, hinges on the development of habitat structures, preferably in advance of a manned landing, and preferably utilizing in-situ resources.

Habitat Structures development with radiation shielding capabilities is one element of the Marshall Space Flight Center's (MSFC) In-Situ Fabrication and Repair (ISFR) Program. ISFR develops technologies for fabrication, repair

\footnotetext{
${ }^{*}$ Project Manager, Habitat Structures Technology Development/SY10

${ }^{\dagger}$ Space Architecture Team Lead, Habitat Structures Technology Development/SY10, AIAA Senior Member

${ }^{\circledR}$ Space Architecture Systems Engineer, Habitat Structures Technology Development/SY10

' Space Architecture Systems Engineer, Habitat Structures Technology Development/SY10
} 
and recycling of tools, parts, and habitats/structures using in-situ resources. The scope of this effort includes the development of Lunar and/or Martian habitat structures for manned missions that maximize the use of in-situ resources to address the following agency topics:

- Bioastronautics Critical Path Roadmap (BCPR) (Ref. 1) risks

o Risks 31-35 (Radiation Health) \& 43-44 (Advanced Life Support (ALS))

- Strategic Technical Challenges defined in Human \&Robotics Technology (H\&RT) Formulation Plan (Ref. 2), including:

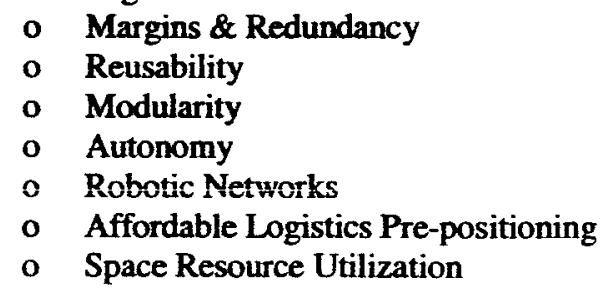

NASA's 1997 Habitats and Surface Construction Technology and Development Roadmap (Ref. 3) identified three broad classes of space and surface habitats and the means of constructing them, as shown in Table 1 .

Table 1. NASA Planetary Surface Habitat Classifications (Ref. 1)

\begin{tabular}{|c|c|l|}
\hline $\begin{array}{c}\text { Class of } \\
\text { Construction }\end{array}$ & \multicolumn{1}{|c|}{ Title } & \multicolumn{1}{|c|}{ Characteristics } \\
\hline I & Pre-Integrated & $\begin{array}{l}\text { Completely built and integrated on Earth before } \\
\text { launch. Lands on surface and stays in one place }\end{array}$ \\
\hline II & Deployable & $\begin{array}{l}\text { Completely built on Earth but may be integrated, } \\
\text { assembled, deployed, erected, inflated, moved or } \\
\text { reconfigured on the lunar/planetary surface }\end{array}$ \\
\hline III & In Situ Resource Utilization (ISRU) & $\begin{array}{l}\text { May be built on Earth, but incorporates in situ } \\
\text { materials on surface or primary structure may use in } \\
\text { situ construction }\end{array}$ \\
\hline
\end{tabular}

The ISFR Program at MSFC is obviously focusing on the development of Class III habitats. As part of this task, a number of in situ material-based construction technologies have been identified, and have been subjected to a rigorous trade study evaluation with respect to exploration and other performance criteria by the Habitat Structures group within NASA/Marshall Space Flight Center's ISFR team.

Top level requirements have been determined as follows:

- Support a pressurized (shirtsleeve) environment for the crew

- Protect the crew from a worst case radiation (galactic cosmic radiation (GCR) \& solar particle events (SPE)) exposure

- Protect the crew from micrometeorites and exhaust plumes

- Initially, be able to be fabricated in advance of a manned crew so as to provide immediate protection (semi-autonomous construction)

- Early, achievable, and visible milestones and successes are required

- Development should be evolutionary and scalable

- Present a psychologically/ergonomically compatible living environment for the crew

However, other top level requirements have been identified in NASA Level 0 Requirements (Ref. 4) and draft Level 1 Requirements documents that include, for example, crew size of 4-6, Spiral 3 extended mission durations of 42-98 days, and up to 4 crew transfers per year.

Therefore, this trade study includes the following content areas: 
1) Description of the technologies evaluated including TRL and $\mathrm{RD}^{3}$ assessments.

2) Statement of the project top-level requirement and assumptions/groundrules.

3) Trade study assessments, criteria, weight factors, and final conclusions/recommendations.

4) Gap analysis.

\section{Trade Study Approach}

\section{A. Construction Products}

The Habitat Structures Team has identified six primary construction product lines represented by twenty distinct product technologies. These construction product lines and technologies, shown in Table II, are primarily based on in-situ materials (with a few noted exceptions). However, it was determined that most integrated construction technologies will still require one or more components be brought from Earth. Therefore, there are some technologies that require "imported" structures or materials, meaning structures or materials that are brought from Earth. A relatively large number of habitat structure configurations can be developed from a relatively small set of in-situ resource-based construction products, including, blocks, raw regolith (loose, bagged, or use of caves/lava tubes), reinforced concrete, and glass products. A much larger group of habitat designs can be developed when these "imported" materials are brought from Earth, including thin films and liners, and foldable, or expandable metal structures.

Table II - ISFR Habitat Structures Construction Product Lines/Technologies

\begin{tabular}{|c|c|}
\hline Construction Product Lines & Specific Construction Technologies \\
\hline \multicolumn{2}{|l|}{ Raw Regolith } \\
\hline & Buried Structures \\
\hline & Sandbags \\
\hline & Subsurface Features \\
\hline \multicolumn{2}{|l|}{ Blocks } \\
\hline & Compacted Regolith \\
\hline & Self-Combustion Synthesis (SCS) \\
\hline & Solid Human Waste \\
\hline & Carved Rock \\
\hline & Plaster/Mortar \\
\hline & Cast Basalt \\
\hline \multicolumn{2}{|l|}{ Reinforced Concrete } \\
\hline & Pre-Cast, Pre-Stressed Panels/Forms \\
\hline & Lunar Contour Crafting \\
\hline & Inflatable Concrete Structures \\
\hline \multicolumn{2}{|l|}{ Deployable Metal Structures } \\
\hline & Foldable Structures \\
\hline & Extendable Structures \\
\hline \multicolumn{2}{|l|}{ Thin Films/Inflatables } \\
\hline & Stand-Alone Inflatables \\
\hline & Liners \\
\hline & Nested Inflatables \\
\hline & Inflatable Structural Support \\
\hline \multicolumn{2}{|l|}{ Glass Products } \\
\hline & Fibers/Rods \\
\hline & Plates \\
\hline
\end{tabular}




\section{B. Integrated Construction Approaches}

It is difficult, if not impossible, to perform an objective evaluation of many of these technologies in a stand-alone configuration. This is true primarily because many of the stand-alone technologies can not, by themselves, satisfy many of the requirements. Therefore, a matrix of all possible configurations representing various combinations of technologies was developed. From this, those that were redundant or not feasible because, for example, there appeared to be insufficient structural support, were then eliminated. From the twenty specific technologies identified previously, a total of ten different, feasible, integrated construction approaches were derived. These integrated construction technologies are as follows:

1) Raw Regolith/Buried, "Imported" Structures

2) Sandbags/Liner

3) Sandbags/Deployable Metal Structure/Nested Inflatable

4) SandbagsiNested Inflatable

5) Cave or Lava Tube/Liner

6) Cave or Lava tube/Nested Inflatable

7) Cave or Lava tube/'Imported" Structure

8) Blocks/Liner

9) Blocks/Deployable Metal Structure/Nested Inflatable

10) Reinforced Concrete/Liner

It should be noted that several technologies identified in Table I do not appear in the above list, including glass fibers/rods/plates, plaster/mortar, and inflatable structural support. These represent support technologies that may or may not be used in various integrated construction approaches, but are not specifically required by any of them.

In this section, other requirements that were derived from various reference mission scenarios are identified. For example, a life cycle of 15 years has been assumed for a Lunar or Martian habitat. In addition, for consistency, we have assumed a habitable, pressurized area/volume consisting of the equivalent of three rectangular rooms, each $20^{\circ}$ x $20^{\prime}$ with $10^{\prime}$ ceilings, or a hemisphere with an equivalent diameter that would support a contained $20^{\circ} \times 20^{\prime} \times 10^{\prime}$ room. Relevant parameters of these two configurations are summarized in Table III. While this assumption does not yet take into account the results of various existing habitat sizing models (Ref. 5,6), it can be used to standardize upmass requirements, required construction support equipment, etc.

Table III - Relevant Physical Parameters of an Assumed Habitat Structure

\begin{tabular}{|l|l|l|}
\hline \multicolumn{1}{|c|}{ Parameter } & \multicolumn{1}{|c|}{ Rectangular Configuration } & \multicolumn{1}{|c|}{ Hemispherical Configuration } \\
\hline Dimensions & $20^{\prime}$ long $\times 20^{\prime}$ wide $\times 10^{\prime}$ high & $\begin{array}{l}34.6^{\prime} \text { diameter, 17.3' high at } \\
\text { center }\end{array}$ \\
\hline Floor Area, $\mathrm{ft}^{2}$ & 400 & 942.4 \\
\hline Volume, $\mathrm{ft}^{3}$ & 4,000 & 10,882 \\
\hline Wall/Ceiling/Roof Area, $\mathrm{ft}^{2}$ & 2,000 & 3,770 \\
\hline
\end{tabular}

\section{Evaluation Criteria}

There are a total of 35 evaluation criteria in this preliminary version of the trade study. These include systems integration, risk levels, current TRL level, degree of development difficulty, resources required, as well as habitation-specific criteria such as the ability to interface with ECLSS components and environment-specific criteria such as radiation shielding capability.

Each criterion has a relative score range of 1 to 3 , with the assignments made on a relative basis from either the best current existing technology or a performance goal. Weighting factors are applied for each criterion ranging in value from 1 to 3 with 3 being the highest priority. The best current system behavior and/or a targeted performance capability are assigned a value of 3 for the individual score.

For the weight factors, safety and other programmatic issues are typically weighted higher compared to specific 
design issues such as the ability to incorporate windows or natural lighting. Similarly, an integrated construction technology that represents more difficulty in controlling safety hazards are assigned a value of 1 versus a technology that might be rated as a 3 due to lower safety implications. Currently, the evaluation criteria are not arranged in priority order and the most relevant are briefly described below:

\section{Critical Resource Savings for Lunar Habitat Missions}

Equivalent system mass is estimated by making a rough calculation of the mass (A) of an aluminum structure equivalent to the size described previously. Projected upmass for each habitat configuration (B) is then calculated, including required "imported" structures, liners, inflatables, and equipment required to inflate, gases, saws, concrete mixers, etc. $B$ is then subtracted from $A$. The larger the result, the better the rating.

\section{Benefit from other technology development programs}

Here, an assessment is performed of non-ISFR work, both for the government and commercially, to see if a given configuration can leverage off existing technology. As an example, the use of caves or lava tubes as habitats are generally rated lower than configurations using concrete because there exists a wealth of information on commercial concrete technologies and resources, and relatively little on the use of caves or lava tubes.

\section{Current TRL Value}

Technology Readiness Levels (TRLs) (Ref. 7) are a systematic metric/ measurement system that supports assessment of the maturity of a particular technology. The TRL approach has been used on-and-off in NASA space technology planning for many years and was recently incorporated in the NASA Management Instruction (NMI 7100) addressing integrated technology planning at NASA. The numerical definitions of the TRLs are given below:

- TRL 1 Basic principles observed and reported

- TRL 2 Technology concept and/or application formulated

- TRL 3 Analytical and experimental critical function and/or characteristic proof-of-concept

- TRL 4 Component and/or breadboard validation in laboratory environment

o TRL 5 Component and/or breadboard validation in relevant environment

o TRL 6 System/subsystem model or prototype demonstration in a relevant environment (ground or space)

o TRL 7 System prototype demonstration in a space environment

- TRL 8 Actual system completed and "flight qualified" through test and demonstration (ground or space)

o TRL 9 Actual system "flight proven" through successful mission operations.

Research \& Development Degree of Difficulty $\left(\mathrm{RD}^{3}\right)$

$\mathrm{RD}^{3}$ (Ref. 8) is a measure of how much difficulty is expected to be encountered in the maturation of a particular technology and is needed to complement existing TRL metrics.

Ability to Withstand Lunar Pressure Differential

It is important to note that a lunar habitat is, in effect, a pressure vessel. A 15 psi pressurized interior with a "hard" vacuum on the exterior will put habitat walls under significant tensile loading that exceeds, in many cases, live and/or dead loads imposed on the structure by people or regolith applied for radiation shielding. In many cases, these dead loads can actually relieve tensile loads on such a pressurized structure. Therefore, any concept that includes a freestanding inflatable is generally rated lower than one that is physically supported on the exterior.

Baseline Radiation Shielding Capability

The inability to provide radiation shielding for a crew for long durations is a potential showstopper for development of any lunar habitat structure. Therefore, potential configurations that inherently provide a higher level of protection (i.e., thick-walled regolith blocks) are rated higher than, for example, a stand-alone inflatable.

Modularity/Expandability

The ability to expand in a modular fashion is a key requirement for habitat structure development. The ease of such expansion is assessed here. 
Processing Hazard Level

Current ISFR habitat planning includes fabrication of at least one structure in the year prior to a manned crew landing such that significant radiation protection is immediately available upon landing. However, it is also anticipated that multiple structures will be fabricated while humans live and work in proximity to habitat fabrication. This criteria then, evaluates potential hazards to a manned crew in close proximity as a function of habitat configuration construction hazards.

\section{Ease of Multiple Egress}

For safety reasons, it is reasonable to expect that surface habitats will be required to support multiple egress routes. This is easier with some design configurations than with others. For example a buried, "imported" structure may offer only one egress route, while a concrete structure on the surface can be designed to incorporate multiple egress routes.

\section{Overall Technical Risk}

This category, includes, for example, the risk associated with the use of laves or lava tubes on the Moon as habitats based on our general lack of data on the location, or even the existence of such geological features at this time.

\section{Trade Study Results}

An initial trade study comparison of the various habitat structures integrated construction technologies has been completed. The end result of this trade study will be used to prioritize the appropriate technologies for future funding. The study is not yet fully complete due to refinement of evaluation criteria/requirements, as well as the potential need for additional technologies to be incorporated. Tabulated results of this initial trade are presented in Table IV.

\begin{tabular}{|c|c|c|}
\hline $\begin{array}{c}\text { INTEGRATED CONSTRUCTION } \\
\text { APPROACH }\end{array}$ & OVERALL SCORE & OVERALL RANKING \\
\hline Sandbags/Liner & 2.124 & 1 \\
\hline Reinforced Concrete/Liner & 2.108 & 2 \\
\hline Blocks/Liner & 1.989 & 3 \\
\hline Cave or Lava Tube/Liner & 1.920 & 4 \\
\hline Sandbags/Nested Inflatable & 1.878 & 5 \\
\hline Cave or Lava Tube/Imported Structure & 1.840 & 6 \\
\hline Cave or Lava Tube/Nested Inflatable & 1.839 & 7 \\
\hline $\begin{array}{c}\text { Sandbags/Deployable Metal } \\
\text { Structure/Nested Inflatable }\end{array}$ & 1.826 & 8 \\
\hline $\begin{array}{c}\text { Raw Regolith/Buried, Imported } \\
\text { Structure }\end{array}$ & 1.770 & 9 \\
\hline $\begin{array}{c}\text { Blocks/Deployable Metal } \\
\text { Structure/Nested Inflatable }\end{array}$ & 1.676 & 10 \\
\hline
\end{tabular}

A quick analysis shows that systems utilizing a liner with external reinforcement tend toward the top of the list, especially those that require less upmass equipment. An interesting footnote is that many lunar base studies advocate a buried structure, but our quick analysis indicates that the mass of required excavation equipment, coupled with the mass of the imported structure itself, may offset other benefits.

The idea of sandbags filled with regolith as a lunar structure is not a new one (Ref. 9), but little work has been done on the incorporation of a liner (for hermeticity, pressure control, etc.). NASAMSFC is currently researching optimum liner materials and configurations for these applications. The use of reinforced concrete has also recently been studied in more detail (Ref. 10,11) and shows promise as a planetary surface construction material. The use of blocks has also been studied in great detail (Ref. 12) and, as more information is obtained in the areas of lunar regolith composition and variance, especially in the south pole, significant advances in the development of these technologies is expected. The development of large quantities of high quality, standardized, lunar regolith simulants, 
will also advance technology developments in lunar construction, as well as in other In Situ Resource Utilization (ISRU) areas.

Future activities include possible addition of new technologies for evaluation, with subsequent definition of potential new integrated construction approaches. In addition, refinement and addition of evaluation criteria will be an ongoing effort. As an example, dust mitigation/control is a criteria that needs to be added. In concert with this, an evaluation of these technologies with respect to the Mars environment will be completed and any synergy between Lunar and Martian applications will be identified. Technology development roadmaps are also currently being developed to support both ISRU and Life Support and Habitation activities at NASA Headquarters. Gap analyses are currently being performed to identify key technical areas requiring further development in order to facilitate the deployment of these structures.

\section{Acknowledgments}

Portions of this work were performed in support of the Marshall Space Flight Center under the Jacobs Engineering/Sverdrup (JE/SvT) Engineering, Science, and Technical Support (ES\&TS) Contract (No. NAS800187). Special thanks to Nathan Brown (NASAMSFC) for his contributions to this paper.

\section{References}

1. Bioastronautics Critical Path Roadmap (BCPR), JSC 62577, Rev. E, April 2, 2004, also located at http://bioastroroadmap.nasa.gov/beta/index.jsp.

2. Human \& Robotics Technology (H\&RT) Formulation Plan, Version 5.1, September 13, 2004.

3. Cohen, M. M. and Kennedy, K. J., "Habitats and Surface Construction Technology and Development Roadmap," in Government Sponsored Programs on Structures Technology (NASA CP-97-206241), Noor, A. and Malone, J., (Eds.), pp. 75-96, November, 1997.

4. Level 0 Exploration Requirements for the National Aeronautics and Space Administration, SA-0001, Rev. Baseline, May 4, 2004.

5. Eckart, P., "Lunar Base Parametric Model," Journal of Aerospace Engineering, Vol. 10, No. 2, April, 1997.

6. Moonraker - Combination Lunar Ascent, Descent, and Surface Habitat Tool, v. 1.2, SpaceWorks Engineering, Inc., October, 2004.

7. Mankins, J.C., "Technology Readiness Levels - A White Paper," April 6, 1995, Advanced Concepts Office/Office of Space Access and Technology, NASA Headquarters.

8. Mankins, J.C., "Research \& Development Degree of Difficulty (R\&D $\left.{ }^{3}\right)$ - A White Paper," July 1, 2000, Advanced Projects Office / Office of Space Flight, NASA Headquarters.

9. Khalili, E.N., "Lunar Structures Generated and Shielded with On-site Materials," Journal of Aerospace Engineering, Vol. 2, No. 3, July, 1989 (also at http://www.calearth.org/lunar/lunar2.htm).

10. Toutanji, H., Glenn-Loper, B., and Schrayshuen, B., "Strength and Durability Performance of Waterless Lunar Concrete," Proceedings of the $43^{\text {rd }}$ AIAA Aerospace Sciences Meeting and Exhibit, AIAA Paper No. AIAA2005-1436, January 11, 2005.

11. Khoshnevis, B., Bodiford, M.P., Burks, K.B., Ethridge, E., Tucker, D., Kim, W., Toutanji, H., and Fiske, M.R., "Lunar Contour Crafting - A Novel Technique for ISRU-Based Habitat Development," Proceedings of the $43^{\text {rd }}$ AIAA Aerospace Sciences Meeting and Exhibit, AIAA Paper No. AIAA-2005-0538, January 11, 2005.

12. Happel, J.A., "Indigenous Materials for Lunar Construction," Applied Mechanics Review, Vol. 46, No. 6, June 1993, pp. 313-325. 